ARTICLE

\title{
Roll-to-roll gravure-printed flexible perovskite solar cells using eco-friendly antisolvent bathing with wide processing window
}

Young Yun Kim (10 1, Tae-Youl Yang ${ }^{1,2}$, Riikka Suhonen ${ }^{3}$, Antti Kemppainen ${ }^{3}$, Kyeongil Hwang ${ }^{1}$, Nam Joong Jeon (iD ${ }^{1} \&$ Jangwon Seo (iD ${ }^{1 \otimes}$

Driven by recent improvements in efficiency and stability of perovskite solar cells (PSCs), upscaling of PSCs has come to be regarded as the next step. Specifically, a high-throughput, low-cost roll-to-roll (R2R) processes would be a breakthrough to realize the commercialization of PSCs, with uniform formation of precursor wet film and complete conversion to perovskite phase via R2R-compatible processes necessary to accomplish this goal. Herein, we demonstrate the pilot-scale, fully R2R manufacturing of all the layers except for electrodes in PSCs. Tert-butyl alcohol (tBuOH) is introduced as an eco-friendly antisolvent with a wide processing window. Highly crystalline, uniform formamidinium (FA)-based perovskite formation via $\mathrm{tBuOH}:$ EA bathing was confirmed by achieving high power conversion efficiencies (PCEs) of $23.5 \%$ for glass-based spin-coated PSCs, and $19.1 \%$ for gravure-printed flexible PSCs. As an extended work, R2R gravure-printing and $\mathrm{tBuOH}: \mathrm{EA}$ bathing resulted in the highest PCE reported for R2R-processed PSCs, $16.7 \%$ for PSCs with R2R-processed $\mathrm{SnO}_{2} /$ FA-perovskite, and $13.8 \%$ for fully R2R-produced PSCs.

\footnotetext{
${ }^{1}$ Division of Advanced Materials, Korea Research Institute of Chemical Technology (KRICT), 141 Gajeong-ro, Yuseong-gu, Daejeon 34114 , Republic of Korea. ${ }^{2}$ Department of Materials Science and Engineering, Chungnam National University, 99 Daehak-ro, Yuseong-gu, Daejeon 34134, Republic of Korea. ${ }^{3}$ Printed electronics processing, VTT Technical Research Centre of Finland Ltd, Kaitoväylä 1, Oulu 90571, Finland. ${ }^{凶}$ email: jwseo@krict.re.kr
} 
$\mathrm{P}$ erovskite solar cells (PSCs) have been intensively investigated as emerging photovoltaics (PVs) owing to the superior inherent advantages of perovskite as a photoabsorber such as long carrier diffusion length, high defect tolerance, high carrier mobility and high absorption coefficient ${ }^{1-6}$. Another crucial benefit of perovskite material is a feasible solution process to deposit thin film, which allows a cost-effective production of highly efficient $\mathrm{PVs}^{7,8}$. So far, both efficiency and stability of PSCs have been considerably improved, but the scalable fabrication remains a big challenge for the successful commercialization of PSCs. Specifically, the roll-to-roll (R2R) process enables high-throughput, low-cost production of flexible and light-weight PSCs, which will expand the applicability of PSCs into a variety of mobile electronic devices, vehicle- and buildingintegrated $\mathrm{PVs}{ }^{9,10}$. There have been only a few reports on the $\mathrm{R} 2 \mathrm{R}$ production of PSCs so far, and even they are only about partial R2R production or R2R running at laboratory scale ${ }^{11-16}$.

In order to realize R2R production of PSCs, uniform, large-area deposition of sequential layers should be achieved. The R2R deposition of charge-transporting layers was already established by many researchers in organic PVs, but R2R deposition of perovskite layers has not yet been fully explored ${ }^{17,18}$. The R2R deposition of perovskite layers contain three key steps; (1) deposition of lead halide precursor through scalable coating techniques, (2) conversion of wet film of precursor state into supersaturation state through solvent removal, and (3) crystallization through thermal annealing. (Fig. 1a).

Uniform, thickness-controlled deposition of precursor solution is important because the uniformity and morphology of the precursor wet-film determine the quality of the resulting perovskite film grown by heterogeneous nucleation and growth. Among various scalable coating methods, gravure printing enables a simultaneous deposition and patterning of a desired layer with high resolution at relatively fast speed ${ }^{15,18,19}$. The potential of gravure printing for PSCs has been proved by us, successfully demonstrating a fabrication of methylammonium lead iodide $\left(\mathrm{MAPbI}_{3}\right) \mathrm{PSCs}^{15}$.

The conversion of wet film of precursor state into the intermediate phase has been considered as a critical step to realizing large-area, scalable production of perovskite film. The

a R2R processing of perovskite layer

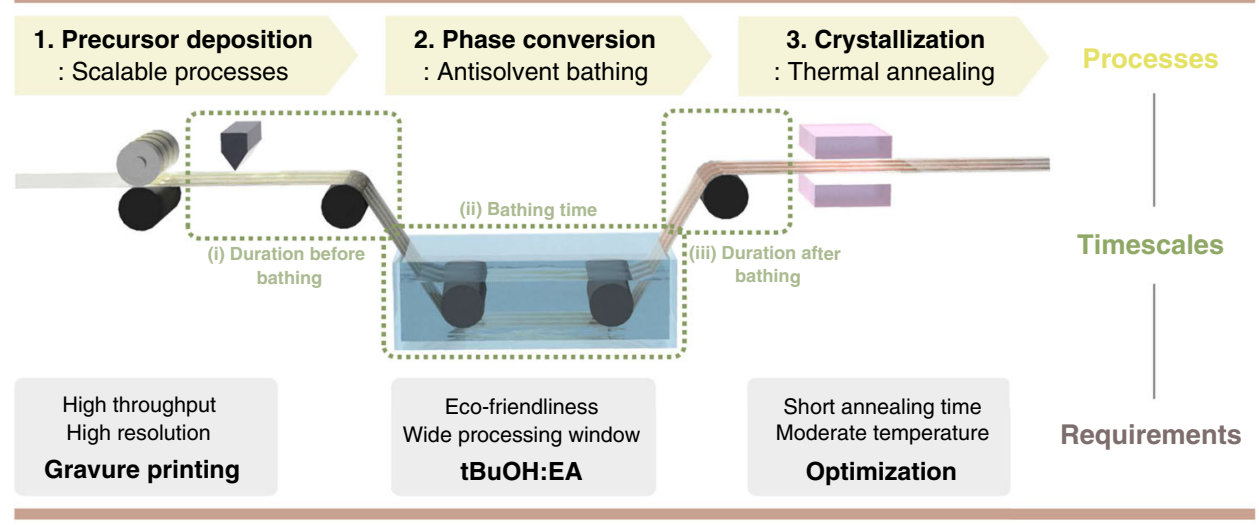

b

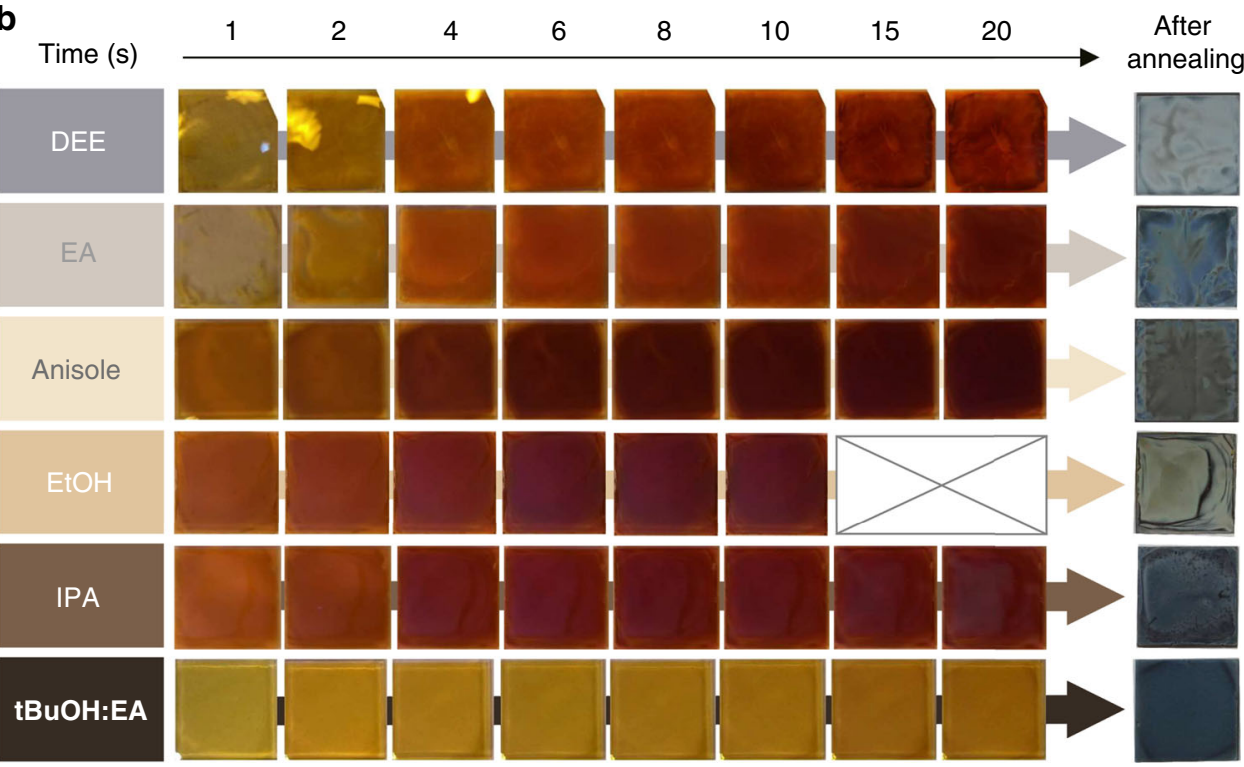

Fig. 1 Formation of high-quality perovskite layers via antisolvent bathing. a Schematic diagram representing R2R processing of perovskite layer. Each step of processing, considerations of each step, and timescales are presented in the figure. $\mathbf{b}$ Photographs of perovskite film after bathing in various antisolvents. The images were recorded as a video and captured at certain times. Final films were obtained by thermal annealing of the intermediate film after bathing for $20 \mathrm{~s}$. 
solvent-engineering method has been widely utilized to achieve high power conversion efficiencies (PCE) in a small-area device of PSCs by reaching a supersaturation state via a rapid antisolvent dripping during the spin-coating ${ }^{5}$. In general, the dripping process involves the physical wiping of solvents driven by centrifugal forces and solvent extraction by chemical affinity. Therefore, this led to a formation of the supersaturated film from the precursor wet film with the retardation mediator by washing out the excess solvent upon the spin-coating.

The dripping process, however, should be modified to be wellfitted into R2R deposition process of large-area perovskite layers. Various alternative methods have been reported including gasblowing ${ }^{20}$, vacuum flash ${ }^{21}$, hot-substrate deposition ${ }^{16,22,23}$, and flash infrared annealing (FIRA) ${ }^{24}$, however, they have still several problems to be solved for R2R applications, which are the use of expensive apparatus, questionable reproducibility, or narrow processing window.

In this work, we choose the antisolvent-bathing approach for $\mathrm{R} 2 \mathrm{R}$ fabrication. The bathing method is the most analogous method to the dripping with a view of the extraction of excess solvent from precursor wet film ${ }^{25,26}$. However, the bathing method requires more precise control of processing conditions to reach a high level of supersaturation state for inducing rapid crystallization. In particular, formamidinium lead iodide $\left(\mathrm{FAPbI}_{3}\right)$ has more complex crystallization behavior with narrow processing window, which makes it more difficult to achieve the high-quality layer via bathing. The bathing method also demands a large amount of solvents, and inevitably discharges the waste solvent. Therefore, antisolvent should meet some criteria such as eco-friendliness and controllable processing window for a practical R2R production at pilot-scale. Several attempts have been made to utilize eco-friendly antisolvents in PSCs, but their usage has been limited only to dripping ${ }^{27,28}$. In addition, the processing windows of antisolvents have not been yet considered thoroughly, especially for bathing ${ }^{29}$.

As a final step, the thermal annealing is crucial for inducing a highly crystalline perovskite film upon crystal nucleation/growth step. The temperature must be lower than the processing temperature limit of the polymer substrate. Shorter annealing time is also preferred to achieve high throughput.

Herein, we demonstrate R2R-processed flexible PSCs at pilot scale through gravure printing, antisolvent bathing and subsequent annealing process. Tert-butanol $(\mathrm{tBuOH})$ is introduced as an eco-friendly solvent into antisolvent-bathing, thereby generating a highly crystalline and uniform perovskite film with wide processing window. As a result of bathing in $\mathrm{tBuOH}$ :EA, we achieve a champion PCE of $23.5 \%$ (in reverse scan) from the glass-used device prepared by spin-coating. The gravure printing of $\mathrm{FAPbI}_{3}$-based perovskite layers is conducted with aid of wide processing window of $\mathrm{tBuOH}$. The best PCE of $19.1 \%$ is achieved in gravure-printed flexible PSCs, which is comparable to the highest PCE of spin-coated flexible PSCs. Full R2R gravure printing of flexible PSCs except for top electrodes is demonstrated at pilot-scale via process optimization to produce a $100-\mathrm{m}$-long roll. The PSCs fabricated by $\mathrm{R} 2 \mathrm{R}$ printed $\mathrm{SnO}_{2}$ /perovskite exhibit a PCE of $16.7 \%$ and $16.5 \%$ when $\mathrm{N} 2, \mathrm{~N} 2, \mathrm{~N} 2^{\prime}, \mathrm{N} 2^{\prime}, \mathrm{N} 7, \mathrm{~N} 7, \mathrm{~N}^{\prime}, \mathrm{N}^{\prime}{ }^{\prime}$ octakis(4-methoxyphenyl)-9, $9^{\prime}$-spirobi[9H-fluorene]-2,2',7,7'-tetramine (Spiro-OMeTAD) is spin-coated and shear-coated as HTL, respectively. The fully R2R printed PSCs with poly(3-hexylthiophene) (P3HT) as HTL show the best PCE of $13.8 \%$, which is the highest PCE ever reported for a fully R2R-processed PSCs.

\section{Results}

Comparison of various eco-friendly antisolvents. In this work, $\mathrm{tBuOH}$ is newly suggested as an eco-friendly antisolvent. Various antisolvents are compared under various safety criteria in Supplementary Table $1^{30-32}$. Common antisolvents widely used for fabricating high-quality perovskite layers are as follows; diethyl ether (DEE), chlorobenzene (CB), chloroform (CF), and toluene (Tol). However, all of them are harmful to human health. We selected eco-friendly alternative antisolvents, such as alcohols or esters, or anisole. Specifically, ethanol (EtOH) and 2-propanol (IPA) as normal-alkyl alcohols, ethyl acetate (EA) as an ester, and anisole as an aromatic were chosen. We also suggested an antisolvent, $\mathrm{tBuOH}$, a tert-alkyl alcohol, which is eco-friendly and has a polarity between those of normal-alkyl alcohols and esters, thereby being expected to show different behavior during antisolvent bathing. Since $\mathrm{tBuOH}$ has a melting point of around $30^{\circ} \mathrm{C}$, we added a small amount of EA to ensure the liquid state of the antisolvent at room temperature. DEE was also selected as a reference.

The time evolutions in appearance and morphology of asprepared films of $\mathrm{FAPbI}_{3}$ after bathing using various antisolvents were investigated (Fig. 1b). As can be seen in Fig. 1b, prolonged bathing in the antisolvents except for $\mathrm{tBuOH}: \mathrm{EA}$ gives rise to a dark wine-red appearance to the film after only a few seconds. This indicates that a nucleation/growth for the generation of perovskite phase occurs at the same time during the antisolventbathing process at room temperature. In addition, specific irregular stains with inhomogeneity are found on the film surface. Such characteristic pattern on the intermediate film is directly transferred to the final film, and the darker intermediate film has a hazy appearance after annealing. The bathing time in these antisolvents should be very short at about 1-2 s, so as to reduce haziness on the surface, and the films do not seem uniform even under that condition. In the case of $\mathrm{tBuOH}: \mathrm{EA}$, however, intermediate films look uniform in appearance and only become slightly darker as time goes on. The final perovskite film obtained by bathing in $\mathrm{tBuOH}$ :EA looks uniform and consistent appearance irrespective of the bathing time.

We attempted to reveal the origins of the different behaviors upon bathing by directly mixing a precursor solution with the antisolvents (Supplementary Fig. 1, and Supplementary Note 1). As not expected for the bathing method, it was found that DEE is not effective in extracting DMF and DMSO. EA and anisole can extract the solvents, but they also disperse some of the $\mathrm{FAPbI}_{3}$, leading to inhomogeneity in the intermediate film with irregular stains and haziness after bathing. It is obvious that IPA partially dissolves FAI while extracting $\mathrm{PbI}_{2}-\mathrm{DMSO}$ from $\mathrm{FAPbI}_{3}$ solution (See Fig. 2a). It is worth noting that $\mathrm{tBuOH}$ :EA can extract DMF and excess DMSO without dispersing $\mathrm{FAPbI}_{3}$ or dissolving FAI in the solution. This aspect explains the homogeneous, uniform $\mathrm{FAPbI}_{3}$ films made using $\mathrm{tBuOH}: \mathrm{EA}$. The strong chemical interaction of $\mathrm{tBuOH}: \mathrm{EA}$ with DMF and DMSO was also confirmed by the shift of the Fourier-transform Infrared (FTIR) spectra (Supplementary Fig. 2).

$\mathrm{FAPbI}_{3}$ film fabricated by using $\mathrm{tBuOH}$ :EA as antisolvent looks uniform and highly crystalline with no trace of $\mathrm{PbI}_{2}$ (Fig. 2a). $\mathrm{FAPbI}_{3}$ films made using other alcohols have distinct peak at around $12.5^{\circ}$, indicating the generation of $\mathrm{PbI}_{2}$. It was probably due to the partial dissolution of $\mathrm{FAI}$. $\mathrm{FAPbI}_{3}$ prepared by using $\mathrm{DEE}, \mathrm{EA}$, anisole, and $\mathrm{tBuOH}$ :EA showed no peaks of $\mathrm{PbI}_{2}$; in particular, for $\mathrm{tBuOH}: \mathrm{EA}$, the film had the highest crystallinity among all the samples.

To gain into more insight of the alkyl effect of alcohol derivatives as antisolvent, we selected n-butyl alcohol $(\mathrm{nBuOH})$ and t-pentyl alcohol $(\mathrm{tPeOH})$ for comparison with $\mathrm{tBuOH}$. $\mathrm{nBuOH}$ has similar viscosity to $\mathrm{tBuOH}$ while $\mathrm{tPeOH}$ has similar polarity to $\mathrm{tBuOH}^{33}$ (Supplementary Figs. 3 and 4, and Supplementary Table 1). The prepared film using $\mathrm{nBuOH}$ looks similar to that of other normal-alkyl alcohols. The irregular stains 


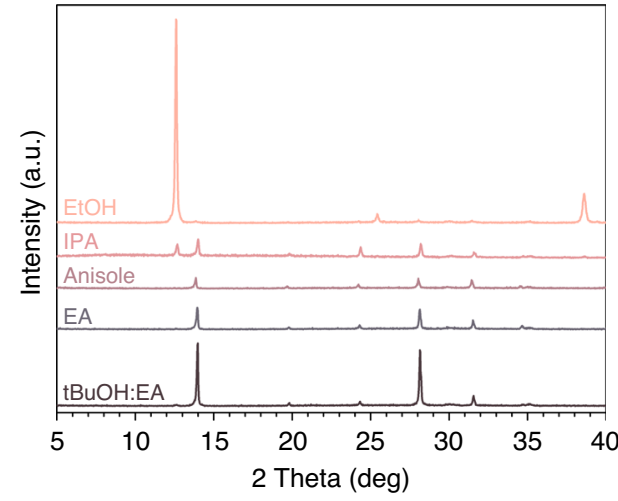

C

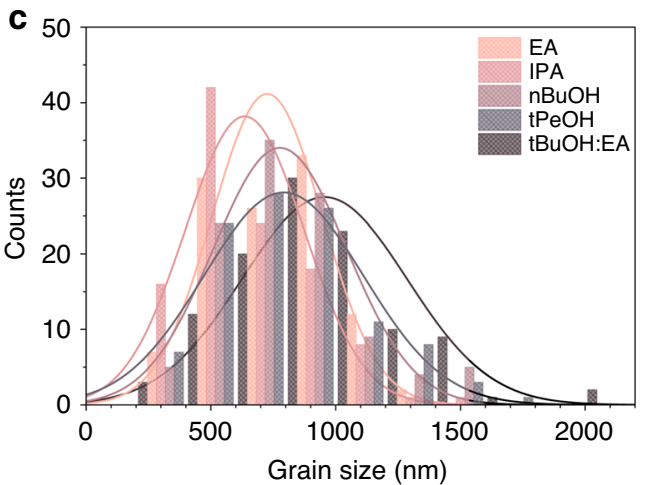

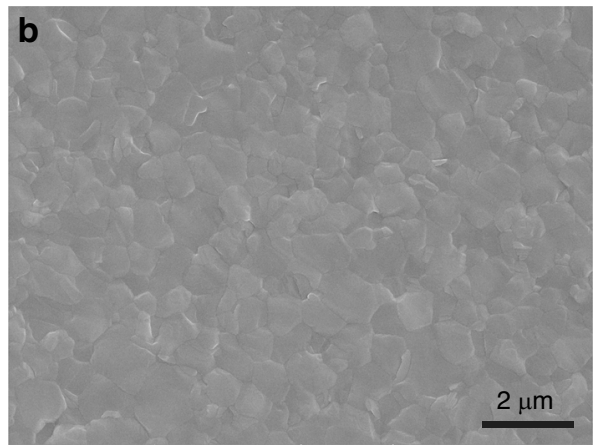

d

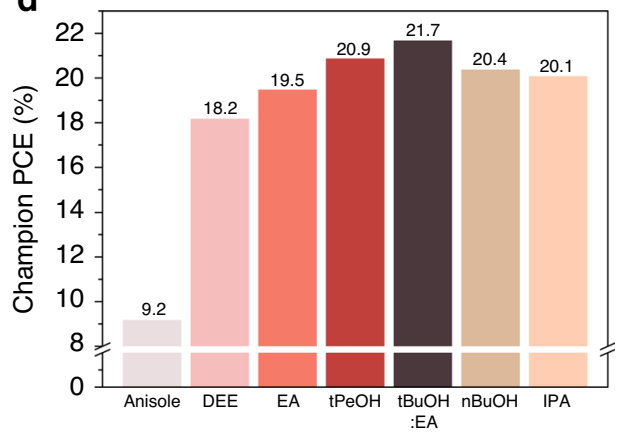

Fig. 2 Characterization of perovskite layers formed by bathing in various antisolvent. a XRD spectra of perovskite films obtained by bathing in various antisolvents. $\mathbf{b}$ SEM image of the perovskite film made by bathing in $\mathrm{tBuOH}: \mathrm{EA}$. c Grain size distribution curves for perovskite films fabricated with various antisolvents. d Champion PCE of PSCs fabricated by bathing in various antisolvents.

are observed on the surface and a trace of $\mathrm{PbI}_{2}$ is also found from $\mathrm{XRD}$ pattern ${ }^{34}$. In contrast, the quality and the appearance of the film fabricated using $\mathrm{tPeOH}$ looks entirely consistent with that using $\mathrm{tBuOH}: \mathrm{EA}$. The role of the antisolvent is to extract the retardation mediator and the excess processing solvent without dissolving the perovskite precursors from the wet film. It is elucidated from this result that the polarity of the antisolvent should be considered to ensure a good quality film with uniform and consistent morphology even for a long bathing time.

The fabricated film using tBuOH:EA has a smooth morphology with a large grain size of $\sim 1 \mu \mathrm{m}$ (Fig. 2b). In the case of EtOH and anisole, the films have a poor surface coverage with a relatively rough surface (Supplementary Fig. 5). In contrast, in the case of $\mathrm{tPeOH}, \mathrm{nBuOH}, \mathrm{EA}$, and IPA, the films exhibit a full surface coverage without the pinholes. The sizes of grains were measured using ImageJ software; results were averaged over 110 grains $^{35}$ (Fig. 2c). The average grain size of $\mathrm{FAPbI}_{3}$ fabricated using $\mathrm{tBuOH}$ :EA is $955 \pm 330 \mathrm{~nm}$, which is much larger than that of $\mathrm{FAPbI}_{3}$ obtained from the other solvents. $(791 \pm 319,777 \pm 267$, $726 \pm 221$, and $636 \pm 238 \mathrm{~nm}$ from $\mathrm{tPeOH}, \mathrm{nBuOH}, \mathrm{EA}$, and IPA, respectively).

We have investigated fluorescent lifetime images (FLIM) and their corresponding time-resolved photoluminescent (TRPL) spectra (Supplementary Fig. 6). From FLIM images, the distribution of the PL lifetimes in the entire area for the film processed with $\mathrm{tBuOH}: \mathrm{EA}$ is much more even as compared to that with DEE. Its average PL lifetime is found to be $101 \mathrm{~ns}$, which is higher than those of the films processed with DEE and EA (60 and $53 \mathrm{~ns}$, respectively). This can support a formation of a highly crystalline and defect-less perovskite film with a good uniformity after the treatment with $\mathrm{tBuOH}: \mathrm{EA}$. The champion PCE of $\mathrm{tBuOH}$ :EA-used PSCs is $21.7 \%$, which is the highest among PSCs treated with various antisolvents (Fig. 2d). The photovoltaic parameters of the champion PCE of PSCs treated with various antisolvents are summarized in Supplementary Table 2. The PCE values of PSCs processed with other antisolvents except for DEE and anisole are around $20 \%$. In particular, a low PCE of $9.2 \%$ for the device fabricated using anisole is mainly attributed to a poor morphology of the perovskite film (as shown in Supplementary Fig. 5).

Processing window of new antisolvent and device performances. As expected from the bathing results of Fig. $2 b$, a wide processing-time window could be anticipated when $\mathrm{tBuOH}: \mathrm{EA}$ is used for the antisolvent bathing. To verify this, we design the modified device fabrication by mimicking $\mathrm{R} 2 \mathrm{R}$ process of a perovskite film as follows; sequential procedures of spin-coating of precursor, stopping at a desired time, subsequent antisolvent bathing, air blowing, and annealing.

Firstly, the processing tolerance for the amount of DMSO was investigated. The amount of DMSO in the precursor solution is a critical factor determining the amount of solvents left in the precursor wet film after deposition, because DMSO has a high boiling point and strong affinity to perovskite precursors. Adjusting the amount of DMSO can alter the maximum duration before unwanted and rapid phase conversion begins, thereby allowing optimal control of the duration between printing and bathing ${ }^{36}$. The use of higher amount of DMSO than 1 equivalent to $\mathrm{FAPbI}_{3}$ in the perovskite precursor solution affords uneven and hazy perovskite films when other common antisolvents, e.g., EA and DEE are used (Supplementary Fig. 7). In the case of $\mathrm{tBuOH}: \mathrm{EA}$, however, the perovskite film looks very uniform without any haziness regardless of the amount of DMSO, from 0.7 to 2 equivalent molar amount to $\mathrm{FAPbI}_{3}$. This tendency is also confirmed in the scanning electron microscope (SEM) images 

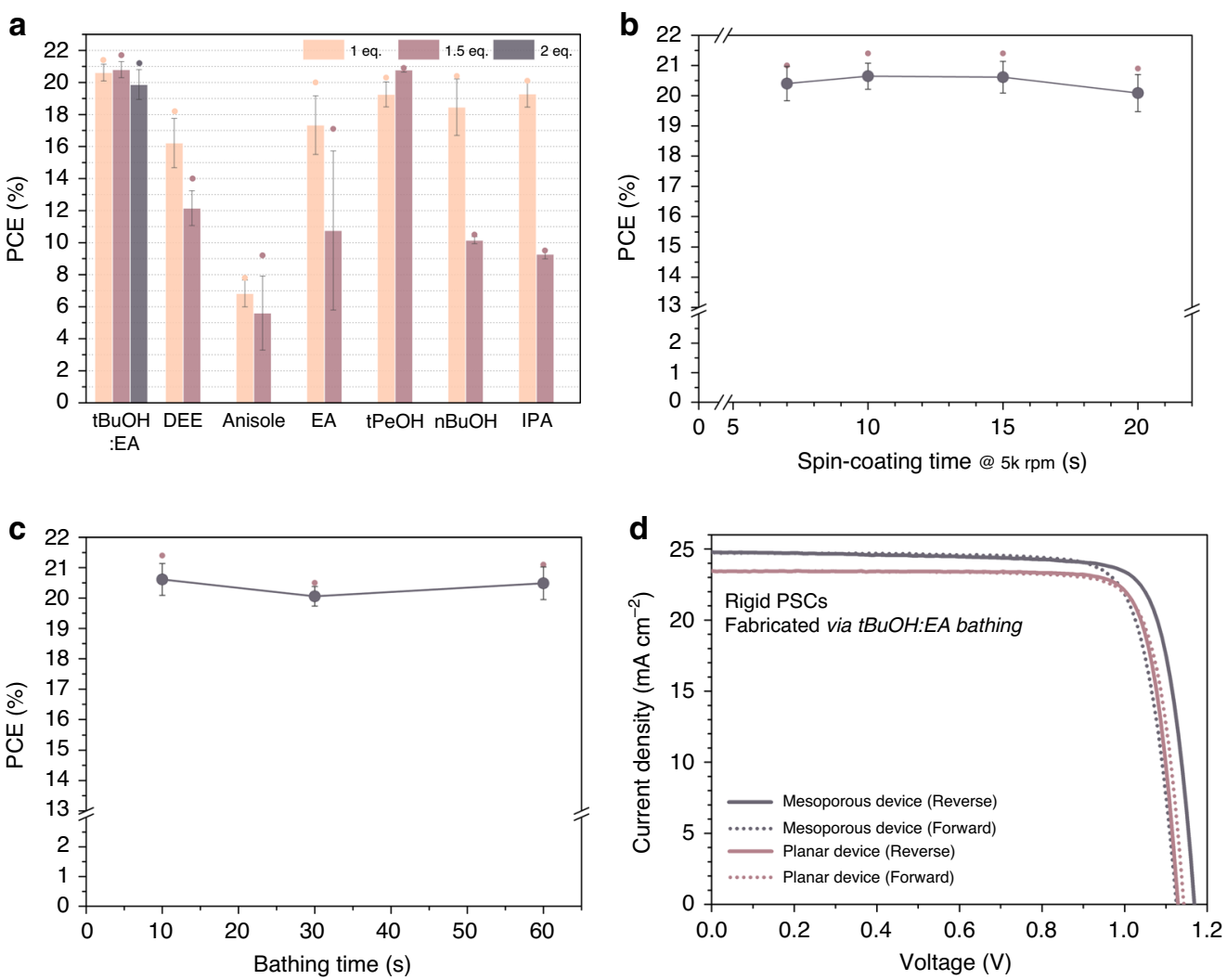

Fig. 3 Processing window of perovskite formation processes via antisolvent bathing and champion device performance. a Average (bar) and champion PCE (circle) of PSCs made by bathing in antisolvents according to amounts of DMSO in the precursor solution with respect to the amount of perovskite. The gray error bars indicate standard deviation of PCEs. b PCE of tBuOH:EA derived PSCs depending on spin-coating duration. $\mathbf{c}$ PCE of PSCs fabricated by $\mathrm{tBuOH}: \mathrm{EA}$ bathing for controlled time. In both figures, indigo dots represent average PCEs, bars indicate standard deviations, and small purple dots mean champion PCEs. d Current density-voltage (J-V) curves of champion devices fabricated by bathing in $\mathrm{tBuOH}$ :EA. Average PCE values were obtained from at least 12 devices for each condition.

(Supplementary Fig. 8). The perovskite films made by tBuOH:EA looked uniform and smooth regardless of the amount of DMSO, while the film made by EA or DEE with an amount of DMSO $>1$ showed a very rough and non-uniform morphology.

Accordingly, PSCs processed by $\mathrm{tBuOH}$ :EA maintain their PCE values with an increasing amount of DMSO (Fig. 3a). PSCs made using other antisolvents exhibit a huge drop of PCE with increasing amount of DMSO except for $\mathrm{tPeOH}$ which has a tendency identical to that of $\mathrm{tBuOH}$. The amount of solvent left in the wet film can be also controlled by adjusting the spincoating duration (Fig. 3b). As expected, a longer spin-coating time can result in a larger amount of the solvent evaporation during the spin-coating. For the devices using $\mathrm{tBuOH}: \mathrm{EA}$, high average efficiencies above $20 \%$ are found irrespective of the spincoating duration. Furthermore, it is noted that varying the bathing time (within $60 \mathrm{~s}$ ) in the antisolvent of $\mathrm{tBuOH}$ :EA also does not affect the device performance significantly (Fig. 3c). The wide processing window of $\mathrm{tBuOH}$ :EA is also confirmed by uniform morphology of perovskite layer fabricated upon various operation conditions (Supplementary Fig. 9).

PSCs fabricated using tBuOH:EA as an antisolvent displayed high PCE under optimized condition (Amount of $\mathrm{DMSO}=1.5$ eq. to $\mathrm{FAPbI}_{3}$, bathing time $=10 \mathrm{~s}$, spin-coating duration at 5000 $\mathrm{rpm}=10 \mathrm{~s}$ ). The champion PCE of rigid, planar PSCs made on indium tin oxide (ITO) substrate and using $\mathrm{SnO}_{2}$ as an electrontransporting layer (ETL) is $22.2 \%$ in reverse scan, and $21.95 \%$ on average (Fig. 3d and Table 1). Mesoporous-structured PSCs based on a blocking- and mesoporous $\mathrm{TiO}_{2}$ as ETL with fluorine-doped tin oxide (FTO) substrate were also fabricated (Fig. 3d). The mesoporous device using $\mathrm{FAPbI}_{3}$ from bathing in tBuOH:EA showed a PCE of $23.5 \%$ in reverse scan, and $22.9 \%$ on average. Dripping of $\mathrm{tBuOH}$ :EA was also effective as bathing, as proven by the similar PCE (Supplementary Fig. 10). Consequently, the use of $\mathrm{tBuOH}: \mathrm{EA}$ as antisolvent during the bathing is expected to guarantee a high PCE of PSCs with wide processing window for the $\mathrm{R} 2 \mathrm{R}$ process.

Table-top gravure-printing of flexible PSCs at lab-scale. Various scalable processes have been applied to replace spin-coating. The coating methods including bar, slot-die, or blade coating have been employed to deposit perovskite layers ${ }^{11,12,16,22,23,37-40}$. These coating methods have an advantage of high-throughput deposition of desired layer, but methods require an additional patterning process after deposition. On the other hand, printing methods allows spontaneous formation of layers with desired shape and size with high resolution ${ }^{41,42}$. PSCs deposited by inkjet printing have recently shown a PCE of above $20 \%$, but the deposition speed of inkjet printing is relatively low ${ }^{41}$. Gravure printing is a printing method that can combine the advantages of both methods, leading to spontaneous, high-throughput deposition of desired layer with arbitrary shape and size $e^{15,18,19}$. For the $\mathrm{R} 2 \mathrm{R}$ process, which requires both high-throughput deposition and high resolution, gravure printing is a suitable process to use.

Table-top gravure printing of $\mathrm{FAPbI}_{3}$-based PSCs was conducted as depicted in Fig. 4a, prior to R2R fabrication at pilot-scale. A printing plate is located at the bottom, with a designed pattern having a specific engraving density to control 
Table 1 Summarized photovoltaic parameters of the devices fabricated in this study.

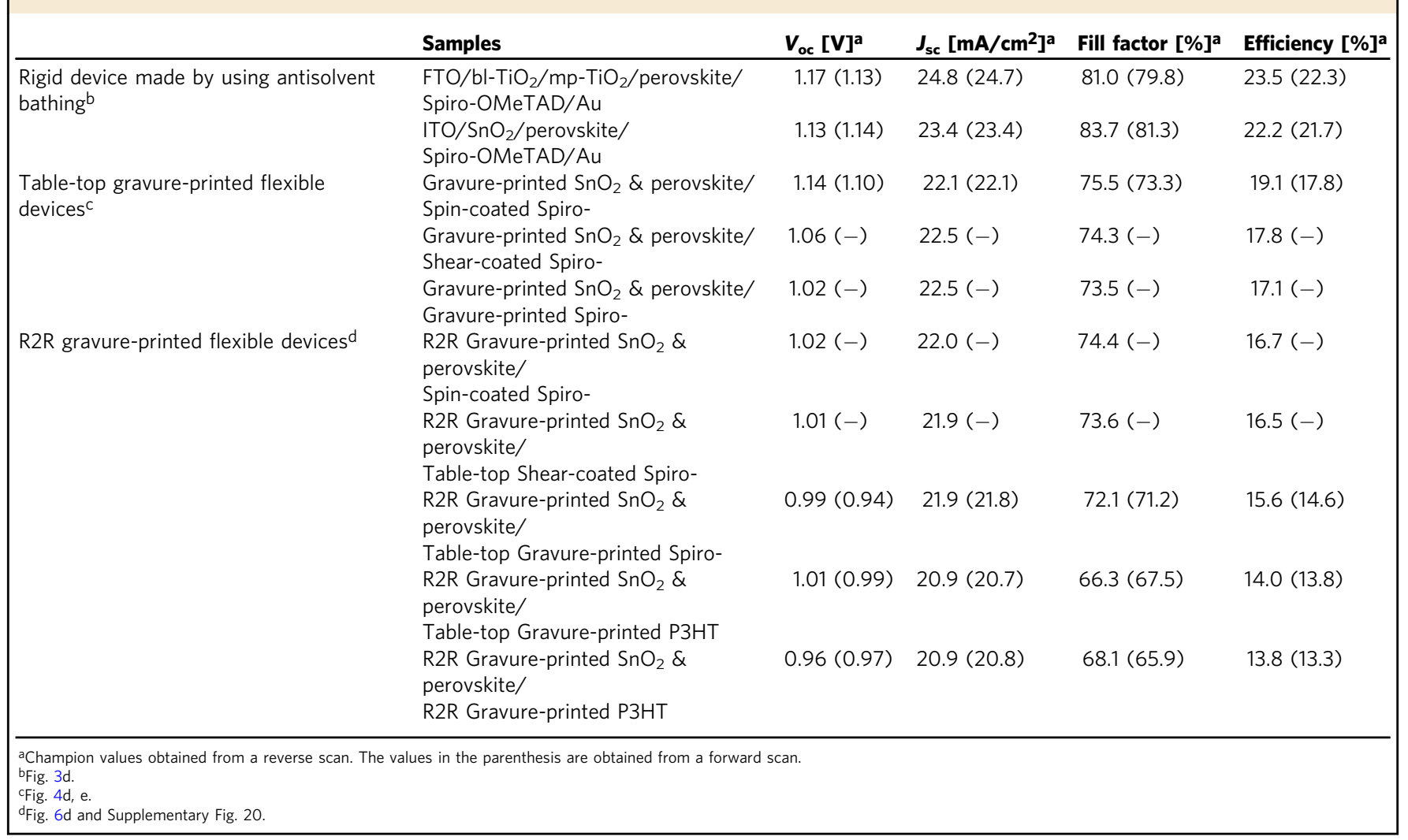

transfer volume of ink. Printing ink is placed on the printing plate and scribed by a doctor blade to be fit in the engraved pattern. The ink is transferred to the substrate by pressure exerted with a roller. $\mathrm{SnO}_{2}$ nanoparticles (NPs) were uniformly gravure-printed on ITO/PET substrates by reducing the surface tension of the ink $^{15}$ (Supplementary Fig. 11). $\left(\mathrm{FAPbI}_{3}\right)_{0.95}\left(\mathrm{MAPbBr}_{3}\right)_{0.05}$ films were uniformly formed on top of the $\mathrm{SnO}_{2}$ layer in large-area by gravure printing and subsequent bathing in $\mathrm{tBuOH}: \mathrm{EA}$ (Supplementary Fig. 12). The perovskite film is formed with large, densely packed grains, and a highly crystalline nature without $\mathrm{PbI}_{2}$, as confirmed by the SEM image and XRD spectrum (Fig. 4b and Supplementary Fig. 13).

Spiro-OMeTAD as an HTL was deposited on the top of the perovskite $/ \mathrm{SnO}_{2}$, all layers of which are formed by gravure printing. The overall device structure is $\mathrm{PET} / \mathrm{ITO} / \mathrm{SnO}_{2} \mathrm{NPs} /$ $\left(\mathrm{FAPbI}_{3}\right)_{0.95}\left(\mathrm{MAPbBr}_{3}\right)_{0.05} /$ Spiro-OMeTAD/Au (Fig. $4 \mathrm{c}$ ). The thicknesses of the layers were 25, 450, 210, and $70 \mathrm{~nm}$ for $\mathrm{SnO}_{2}, \quad\left(\mathrm{FAPbI}_{3}\right)_{0.95}\left(\mathrm{MAPbBr}_{3}\right)_{0.05}$, Spiro-OMeTAD, and $\mathrm{Au}$, respectively. Although we previously demonstrated successful gravure printing of Spiro-OMeTAD on $\mathrm{MAPbI}_{3}$, gravure-printed Spiro-OMeTAD on top of FA-based perovskite was not as effective as printing on $\mathrm{MAPbI}_{3}$ because of the rough surface of the FA-based perovskite layer and the low viscosity of the SpiroOMeTAD solution $^{15}$ (Fig. $4 \mathrm{~d}$ and Table 1). Instead, SpiroOMeTAD was deposited by solution shear-coating, which is basically receding meniscus coating with a low-angle blade 22,38 (Supplementary Fig. 14). The low viscosity and highly volatile characteristic of the Spiro-OMeTAD solution make it more suitable for solution shear-coating than for gravure-printing. PSCs fabricated by all scalable processes including gravure printing of $\mathrm{SnO}_{2} /\left(\mathrm{FAPbI}_{3}\right)_{0.95}\left(\mathrm{MAPbBr}_{3}\right)_{0.05}$ and shear-coating of Spiro-OMeTAD showed PCE of $17.8 \%$.

The champion PCE of flexible PSCs based on gravure-printed $\mathrm{SnO}_{2} /\left(\mathrm{FAPbI}_{3}\right)_{0.95}\left(\mathrm{MAPbBr}_{3}\right)_{0.05}$ and spin-coated Spiro-OMeTAD is $19.1 \%$ in reverse scan and $18.45 \%$ on average, which is comparable to the PCE of the best flexible PSCs based on a spincoating ${ }^{4-45}$ (Fig. 4e and Table 1). The PCE obtained from maximum power point tracking measurement (MPPT) is $18.8 \%$, which is very close to the PCE obtained from the current densityvoltage scan in the reverse direction. Short-circuit current density $\left(J_{\text {sc }}\right)$ was well-matched with the value obtained from external quantum efficiency (EQE) measurement (Supplementary Fig. 15). The average performance of gravure-printed PSCs is open-circuit voltage $\left(V_{\mathrm{oc}}\right)$ of $1.10 \mathrm{~V}, J_{\mathrm{sc}}$ of $22.1 \mathrm{~mA} \mathrm{~cm}^{-2}$, fill factor (FF) of $73.0 \%$, and PCE of $17.8 \%$ (Averaged from 24 devices. Supplementary Figs. 16 and 17).

Pilot-scale R2R gravure-printing of flexible PSCs. We attempt to extend our approach based on antisolvent-bathing process for gravure-printed flexible PSCs into R2R fabrication at pilot-scale, which still remains several issues to be delicately considered, such as the large-scale preparation of the perovskite ink, the feasible short processing time, the choice of the cost-effective HTL, etc.

For the perovskite ink, the viscosity of the precursor solution was optimized to deposit a proper thickness with high resolution in $\mathrm{R} 2 \mathrm{R}$ printing and achieve a sophisticated pattern. To print layers with high resolution, the viscosity of the ink should be increased, or the transfer volume should be smaller to prevent ink from spreading too much. The former is our best choice with respect to cost-effectiveness and reliability. We prepared a highly concentrated solution of perovskite precursor and found that the viscosity of the solution dramatically could be increased from 7.4 to $23.9 \mathrm{mPa}$ at $100 \mathrm{~s}^{-1}$ (Fig. 5a). We investigated the viscosity effect of perovskite precursor solution on the resolution of gravure-printed film by demonstrating a sophisticated pattern of the perovskite film (Fig. $5 \mathrm{~b}$ and c). Upon increasing the solution viscosity, the resolution of resulting patterns is improved. The 
a

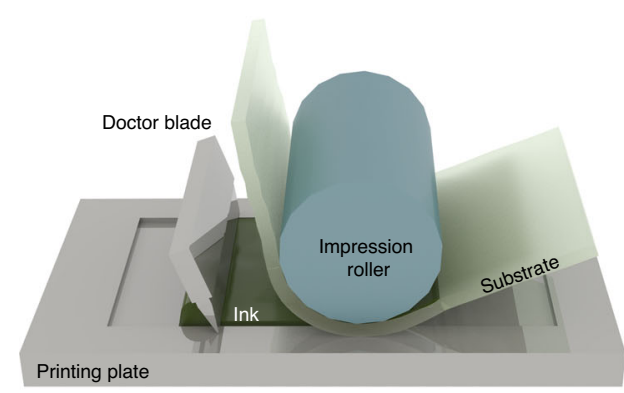

C
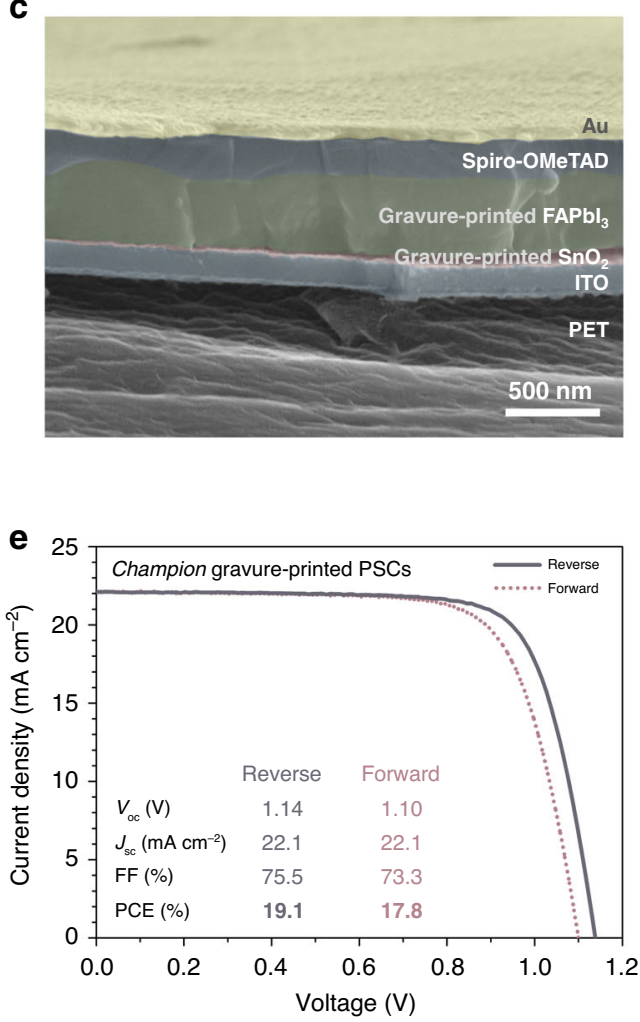

b
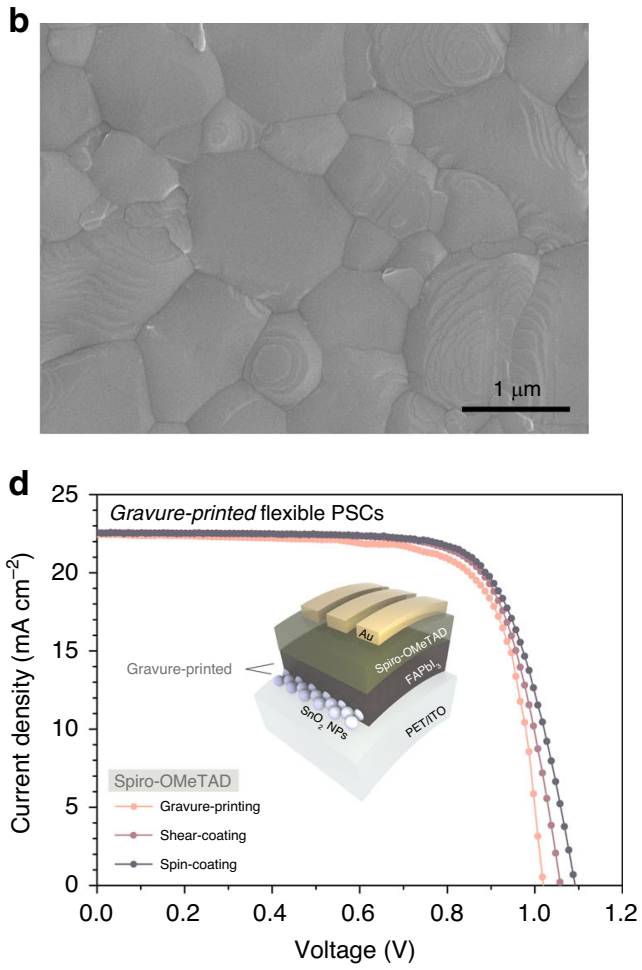

f

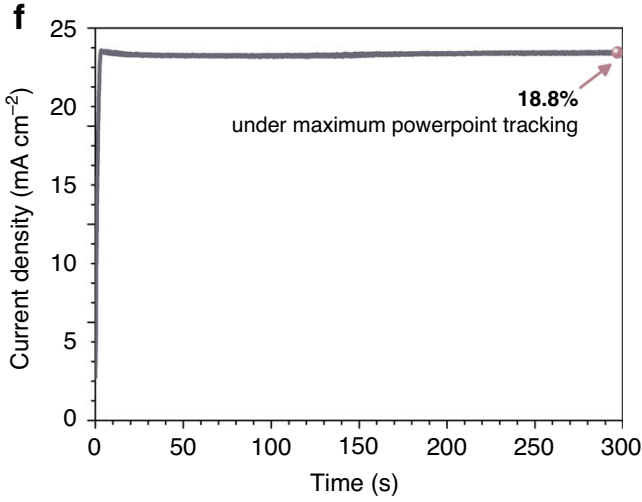

Fig. 4 Table-top gravure-printing of multi-cation flexible PSCs. a Schematic illustration of table-top gravure printing. b SEM image of perovskite film fabricated by table-top gravure printing and subsequent bathing in $\mathrm{tBuOH}$ :EA. c Cross-sectional SEM image of flexible PSCs made by table-top gravure printing. Each layer was colored differently to distinguish it from the others. $\mathrm{FAPb}_{3}$ indicates $\left(\mathrm{FAPb}_{3}\right)_{0.95}\left(\mathrm{MAPbBr}_{3}\right)_{0.05}$. (inset) Diagram illustrating the structure of device used in this study. $\mathbf{d}$ Representative J-V curves of gravure-printed PSCs with Spiro-OMeTAD. Spiro-OMeTAD was deposited by spincoating (indigo), shear-coating (purple) or gravure-printing (salmon). e A J-V curve of champion device fabricated by gravure-printing. $\mathbf{f}$ Efficiency of the champion devices measured by MPPT technique.

edges of patterns look sharper and tailing is reduced. In consideration of pattern definition and thickness of the film, we determine that the optimum concentration of perovskite solution for $\mathrm{R} 2 \mathrm{R}$ is $1.69 \mathrm{M}$.

$\mathrm{R} 2 \mathrm{R}$ production of flexible PSCs at pilot-scale was successfully conducted via sequential $\mathrm{R} 2 \mathrm{R}$ gravure printing of $\mathrm{SnO}_{2} \mathrm{NPs}$, perovskite, and $\mathrm{P} 3 \mathrm{HT}$ as illustrated in Fig. 6a. In this demonstration of R2R, P3HT was selected as HTL because of the lower cost and better printability as previously shown in OPVs, even though the device using Spiro-OMeTAD exhibited higher efficiency $7,17,18 . \mathrm{SnO}_{2} \mathrm{NPs}$ were $\mathrm{R} 2 \mathrm{R}$ gravure-printed followed by short-term annealing. Perovskite precursor solution was first R2R gravure-printed; then, the as-deposited film was exposed to air-blowing from an air knife to adjust the amount of excess processing solvent, and passed through the tBuOH:EA bath to convert phase to intermediate phase, and finally annealed in a hot oven to be crystallized. P3HT was also R2R gravure- printed, and thermally annealed. The whole procedure was recorded as Supplementary Movie 1 and Supplementary Fig. 18.

As a result, we successfully attained a 30-cm-wide, 100-m-long roll of fully R2R-processed PSCs except for the Au metal (Fig. 6b). Uniform, pin-hole free films of $\mathrm{SnO}_{2}$, perovskite, and P3HT layers were successfully deposited by R2R gravure printing (Supplementary Fig. 19). The roll was cut into sheets and Au electrode was formed by evaporation. The structure of the device is shown in Fig. 6c. The thicknesses of the layers are 40, 400, 180, and $100 \mathrm{~nm}$ for $\mathrm{SnO}_{2},\left(\mathrm{FAPbI}_{3}\right)_{0.95}\left(\mathrm{MAPbBr}_{3}\right)_{0.05}, \mathrm{P} 3 \mathrm{HT}$, and $\mathrm{Au}$, respectively.

The quality of R2R gravure-printed $\left(\mathrm{FAPbI}_{3}\right)_{0.95}\left(\mathrm{MAPbBr}_{3}\right)_{0.05}$ was verified by the fabrication of flexible PSCs based on R2R gravure-printed $\mathrm{SnO}_{2} /\left(\mathrm{FAPbI}_{3}\right)_{0.95}\left(\mathrm{MAPbBr}_{3}\right)_{0.05}$ and SpiroOMeTAD HTL (Fig. 6d and Table 1). Spiro-OMeTAD was either spin-coated or solution shear-coated, the same as the tabletop printed perovskite. PSCs composed of R2R printed $\mathrm{SnO}_{2}$ / 


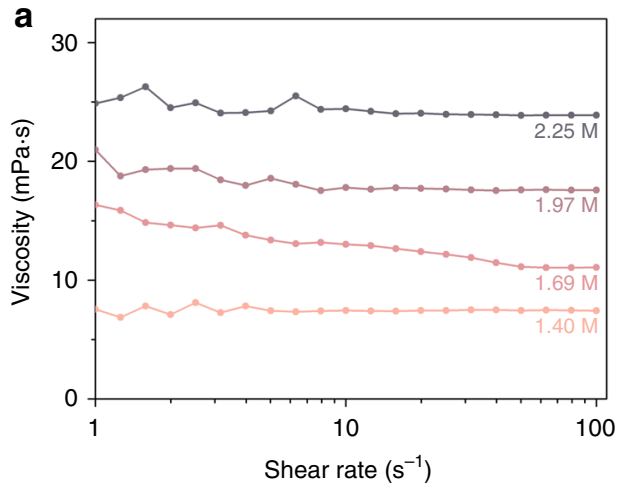

C

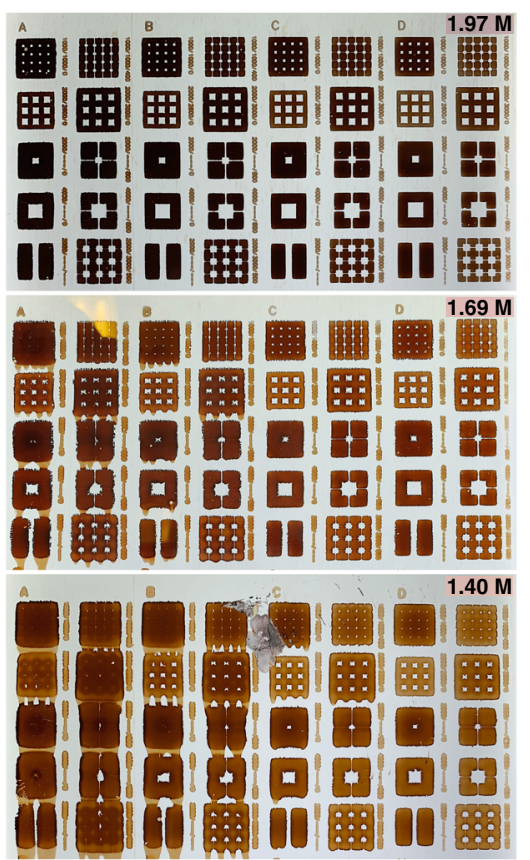

Fig. 5 Modulation of perovskite inks and impact on the resolution of gravure-printed pattern. a Viscosity of perovskite precursor solutions having different concentrations. Images of (b) printing plate and (c) printed perovskite patterns on PET substrate with different concentrations.

$\left(\mathrm{FAPbI}_{3}\right)_{0.95}\left(\mathrm{MAPbBr}_{3}\right)_{0.05}$ and spin-coated Spiro-OMeTAD result in a high PCE of $16.7 \%$, which is the best efficiency among PSCs from R2R-processed perovskite ${ }^{13,14,46,47}$. Solution shearcoating of Spiro-OMeTAD was also applied to the R2R-processed perovskite, resulting in a device with $16.5 \%$ of PCE, which value is almost the same to that from spin-coated HTL. We also attempted to apply gravure printing to deposit Spiro-OMeTAD and $\mathrm{P} 3 \mathrm{HT}$ as a HTM on the top of R2R gravure-printed $\mathrm{SnO}_{2} /$ $\left(\mathrm{FAPbI}_{3}\right)_{0.95}\left(\mathrm{MAPbBr}_{3}\right)_{0.05}$, which resulted in slightly lower performance for Spiro-OMeTAD than other processing methods (Supplementary Fig. 20 and Table 1). Fully R2R gravure-printed PSCs showed PCE of $13.8 \%$ from scan in reverse direction, and $13.55 \%$ on average when P3HT was used as HTL. This is the highest PCE ever reported for fully R2R-processed PSCs ${ }^{11,16}$ (Fig. 6e and Table 1). Note that the P3HT-based devices fabricated by table-top or R2R gravure printing showed almost identical efficiencies, revealing the effectiveness of R2R gravureprinting at a pilot scale (Supplementary Fig. 20 and Table 1). Average PCE from fully R2R-processed devices was $12.4 \%$, with relatively narrow distribution, which illustrates the reliable production of PSCs by sequential R2R gravure printing (Supplementary Fig. 21). The stability of the fully R2Rprocesssed PSCs was investigated by fabrication of the PSCs from the different part of the as-prepared roll $\left(\mathrm{PET} / \mathrm{ITO} / \mathrm{SnO}_{2} /\right.$ $\left.\left(\mathrm{FAPbI}_{3}\right)_{0.95}\left(\mathrm{MAPbBr}_{3}\right)_{0.05} / \mathrm{P} 3 \mathrm{HT}\right)$ for every few days, by randomly cutting into sheets and evaporating $\mathrm{Au}$ electrodes (Supplementary Fig. 22). The PSCs made after almost 40 days from the production of the roll showed similar levels of PCE, indicating the high storage stability and reliability of the PSCs made by R2R gravure printing and the process itself. The largearea applicability and reliability of the $\mathrm{R} 2 \mathrm{R}$ gravure printing was confirmed by a slight decrease in PCE of large-area $\left(1 \mathrm{~cm}^{2}\right)$ devices compared to that of the smaller devices (Supplementary Fig. 23). We believe that the device performance for fully R2Rprocessed PSCs would be obviously enhanced by incorporation of new HTL suitable for R2R process. Our approach using ecofriendly antisolvent bathing with a wide processing window can be universally applied into gravure-printed flexible PSCs at lab \& pilot-scale, thus offering an effective way toward R2R fabrication of flexible PSCs with high efficiency.

\section{Discussion}

In conclusion, we demonstrated R2R-processed flexible PSCs at pilot scale through gravure-printing, antisolvent bathing, and subsequent annealing process. As an eco-friendly anti-solvent, we choose tert-butanol $(\mathrm{tBuOH})$, which was used for antisolventbathing. The mixed co-solvent of $\mathrm{tBuOH}$ :EA offers a formation of a highly crystalline and uniform perovskite film with wide processing window. As a result of antisolvent-bathing, we achieved a champion PCE of $23.5 \%$ (in reverse scan) from the glass-used spin-coated device. The gravure printing of $\mathrm{FAPbI}_{3}$-based perovskite layers was conducted and the best PCE of $19.1 \%$ was achieved in gravure-printed flexible PSCs, which is one of the highest PCE of flexible PSCs to the best of our knowledge. As an extended work, we attempted to fabricate full R2R gravure printing of flexible PSCs except for top electrodes at a pilot-scale via process optimization to successfully demonstrate a manufacturing of 100-meter-long roll and a high PCE exceeding 16\% and $13 \%$, when Spiro-OMeTAD and P3HT was used as HTL, respectively. We believe that this work will pave a new way for high throughput, low-cost production of flexible PSCs at larger scale via $\mathrm{R} 2 \mathrm{R}$ processes in the near future.

\section{Methods}

Chemicals. For perovskite layer, lead (II) iodide (99.999\%, ultra dry) from Alfa Aesar, lead (II) bromide (perovskite precursor grade) from TCI, formamidinium iodide (FAI, Greatcell Solar), methylammonium iodide (MAI, Greatcell Solar), methylammonium bromide (MABr, Greatcell Solar) and methylamine hydrochloride ( $\geq 98 \%$, MACl, Sigma-Aldrich)) were used. Tin (IV) oxide solution ( $15 \%$ in $\mathrm{H}_{2} \mathrm{O}$ ) was purchased from Alfa Aesar. Titanium diisopropoxide bis(acetylacetonate) ( $75 \mathrm{wt} \%$ in isopropanol), Lithium bis(trifluoromethanesulfonyl)imide ( $\geq 99 \%$, Li-TFSI) and 4-tert-butyl pyridine (98\%, TBP) were purchased from SigmaAldrich. N2,N2,N2',N2',N7,N7,N7',N7'-octakis(4-methoxyphenyl)-9,9'-spirobi [9H-fluorene]-2,2',7,7'-tetramine (99\%, Spiro-OMeTAD), and Tris(2-(1H -pyrazol-1-yl)-4-tert-butylpyridine) - cobalt(III) Tris(bis(trifluoromethylsulfonyl) imide)) (>99\%, FK209 Co(III) TFSI) were purchased from LumTec. Mesoporous $\mathrm{TiO}_{2}$ paste was purchased from ShareChem. Poly(3-hexylthiophene) (\#4002-E or 
a
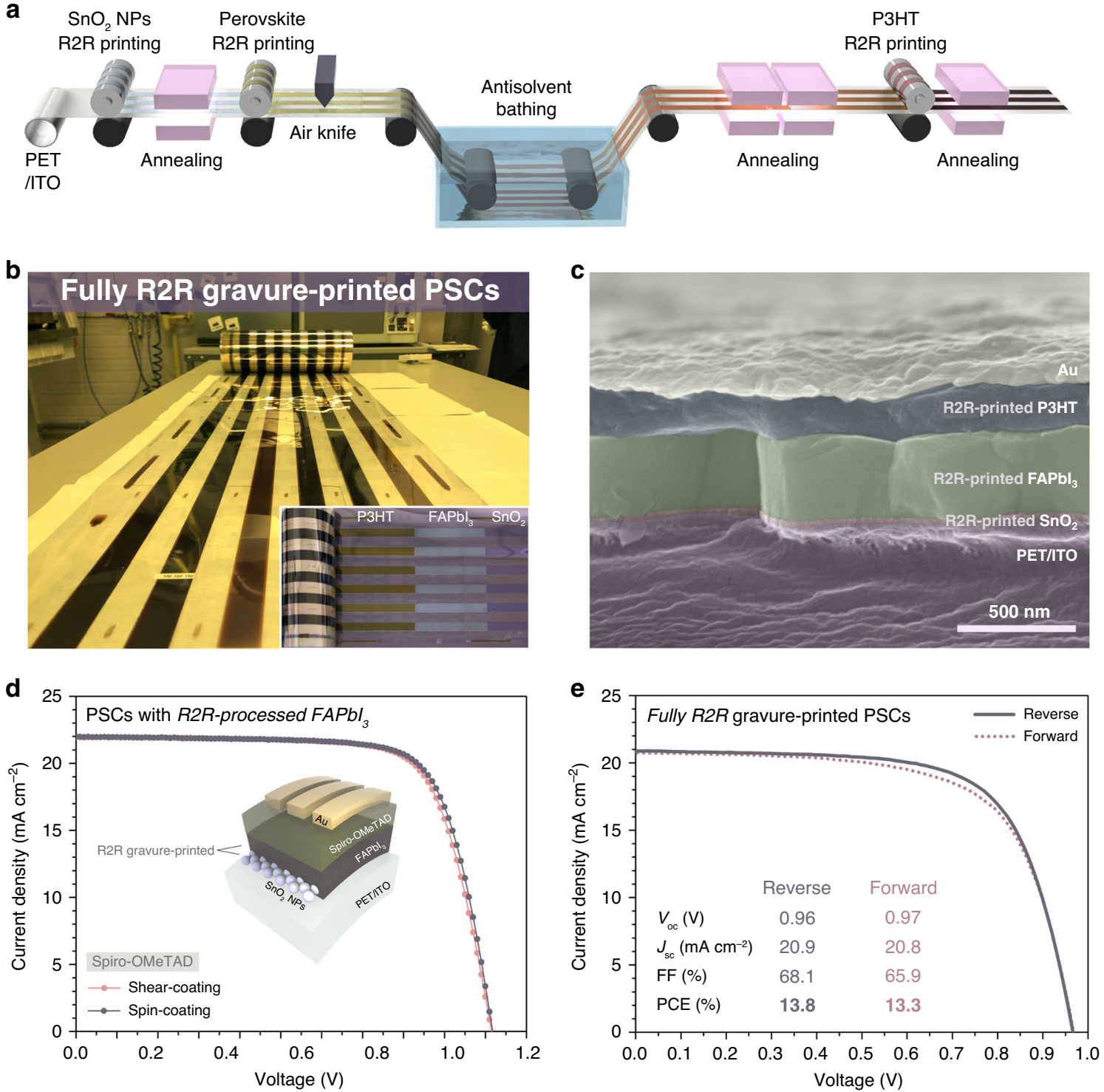

Fig. 6 Fully R2R gravure printing of PSCs except electrodes. a Diagram showing R2R processing for the fabrication of flexible PSCs. b Photograph of fully R2R-processed PSCs. (inset) Image of a R2R-processed roll showing constituent layers of PSCs after removing each layer manually. c Cross-sectional SEM

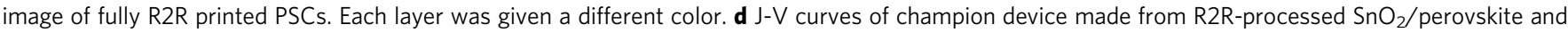
Spiro-OMeTAD (shear-coating: purple, spin-coating: indigo). e The J-V curves of fully R2R gravure-printed PSCs. FAPbl ${ }_{3}$ denotes $\left(\mathrm{FAPbl}_{3}\right)_{0.95}\left(\mathrm{MAPbBr}_{3}\right)_{0.05}$.

\#4002-EE) was purchased from Rieke Metals. All the other chemicals including organic solvents were purchased from Sigma-Aldrich if they are not noted.

Rigid device fabrication. For the $\mathrm{TiO}_{2}$-based devices, a dense $\mathrm{TiO}_{2}$ layer was deposited on a fluorine-doped $\mathrm{SnO}_{2}$ subtrate (FTO, Pilkington, TEC8) by spray pyrolysis of titanium diisopropoxide bis(acetylacetonate) solution in ethanol at $450{ }^{\circ} \mathrm{C}$. Mesoporous $\mathrm{TiO}_{2}$ layer was then deposited on the top of the blocking $\mathrm{TiO}_{2}$ layer by spin-coating of diluted solution (2-methoxyethanol:terpineol $=3.5: 1$ by v/ v) of $\mathrm{TiO}_{2}$ paste followed by thermal annealing at $500^{\circ} \mathrm{C}$ for $1 \mathrm{~h}$. Li-TFSI solution in acetonitrile was spin-coated on the $\mathrm{TiO}_{2}$ layer, then annealed at $500{ }^{\circ} \mathrm{C}$. For $\mathrm{SnO}_{2}$ layer, diluted $\mathrm{SnO}_{2}$ dispersion (1:5 in water by $\left.\mathrm{v} / \mathrm{v}\right)$ was spin-coated on the ITO substrate and annealed at $100^{\circ} \mathrm{C}$. A perovskite solution was prepared by 1.26 mmol of FAI and $\mathrm{PbI}_{2}$, and $0.0632 \mathrm{mmol}$ of $\mathrm{MABr}, \mathrm{PbBr}_{2}$, and $\mathrm{MACl}$ into $0.8 \mathrm{~mL}$ of DMF and $0.15 \mathrm{~mL}$ of DMSO. The perovskite layer was formed by a multi-step spin-coating of the precursor solution at 500, 1000, and $5000 \mathrm{rpm}$. After spincoating, the substrate was dipped immediately in the bath filled with antisolvent. The resulting substrate was blown by compressed air to remove remnant antisolvent on the substrate, then placed on the hot plate at $100^{\circ} \mathrm{C}$. For the champion $\mathrm{TiO}_{2}$-based device, butylammonium iodide dissolved in IPA was spin-coated on the top of perovskite layer at $4000 \mathrm{rpm}$ for $30 \mathrm{~s}$ and annealed at $100^{\circ} \mathrm{C}$ for $5 \mathrm{~min}$. A
Spiro-OMeTAD was dissolved in chlorobenzene $\left(0.0909 \mathrm{~g} \mathrm{~mL}^{-1}\right)$ with $23 \mu \mathrm{L}$ of LiTFSI/Acetonitrile $\left(540 \mathrm{mg} \mathrm{ml}^{-1}\right), 39 \mu \mathrm{L}$ of TBP, and $10 \mu \mathrm{L}$ of FK209/acetonitrile $\left(0.376 \mathrm{~g} \mathrm{ml}^{-1}\right)$. The Spiro-OMeTAD solution was spin-casted at $2000 \mathrm{rpm}$ for $30 \mathrm{~s}$ The devices were completed by thermal evaporation of Au with shadow mask to define cell area.

Fabrication of gravure printed, flexible PSCs at a lab-scale. A ITO-coated PET roll (Eastman Flexvue OC50) was used as a substrate. The ITO was selectively patterned by rotary screen printing of an etching paste. (HiEP-300, P \& P Solution Co., Ltd) The roll was used without further purification. For the laboratory-scale printing tests, ITO/PET roll was cut into individual sheets. The gravure printing at a laboratory-scale was conducted by using a table-top gravure-printing machine (Labratester, Norbert Schläfli Maschinen). $\mathrm{SnO}_{2}$ nanoparticles were diluted by mixture of water and IPA (4:1 by v/v) to reduce surface tension, then gravure printed by a printing plate with an engraved pattern of 120 lines $\mathrm{cm}^{-1}$, at a speed of $18 \mathrm{~m} \mathrm{~min}^{-1}$. A resulting film was annealed in a hot oven at $120^{\circ} \mathrm{C}$ for $5 \mathrm{~min}$. For a perovskite layer, $0.5 \mathrm{~mL}$ of the precursor solution was dispensed on the printing plate with an engraved pattern having a line density of 120 lines $\mathrm{cm}^{-1}$, then printed at a speed of $18 \mathrm{~m} \mathrm{~min}^{-1}$. The freshly printed film was dried for $1 \mathrm{~min}$, then immersed in a bath filled with an antisolvent mixture of tert-butyl alcohol and EA 
(7:3 by v/v). After $30 \mathrm{~s}$ of bathing, the film was blown by compressed air, then annealed in the oven at $120^{\circ} \mathrm{C}$ for $30 \mathrm{~min}$. A Spiro-OMeTAD solution with additives was formed by either spin-coating, gravure-printing, or shear-coating. For the spin-coating, the Spiro-OMeTAD solution was spin-coated at $2000 \mathrm{rpm}$ for 30 s. For the gravure-printing, the Spiro-OMeTAD solution was dispensed at the printing plate having a line density of 100 lines $\mathrm{cm}^{-1}$, then printed at a speed of $18 \mathrm{~m} \mathrm{~min}^{-1}$. Shear-coating of Spiro-OMeTAD was conducted by using a table-top multicoater (PMC-200, PEMS, Republic of Korea) equipped with glass blade. A solution was placed on the top of the substrate having a gap with a blade of $100 \mu \mathrm{m}$, then coated by a rate of $10 \mathrm{~mm} \mathrm{~s}^{-1}$. Au electrodes were evaporated by thermal evaporation with a shadow mask to define the cell area.

R2R printing of PSCs. R2R gravure printing was conducted by using a custombuilt pilot-scale R2R printing machine ${ }^{15}$. A $100 \mathrm{~m}$-long PET roll with patterned ITO electrode was used as a substrate. The roll was $\mathrm{Ar} / \mathrm{N}_{2}$ plasma-treated, then $\mathrm{SnO}_{2}$ nanoparticles were roll-to-roll gravure printed at a speed of $8 \mathrm{~m} \mathrm{~min}^{-1}$ followed by annealing at $120^{\circ} \mathrm{C}$ for $30 \mathrm{~s}$ by hot air oven. The perovskite precursor solution was made to have a concentration of $1.69 \mathrm{M}$, and R2R gravure printed after plasma treatment at a speed of $3 \mathrm{~m} \mathrm{~min}^{-1}$. After printing of wet-film, the roll was blown by air knife to remove extra solvent from wet-film, then passed through a bath filled with the antisolvent mixture of $\mathrm{tBuOH}$ and EA for $10 \mathrm{~s}$. Note that it is not necessary to substitute the antisolvent during R2R printing of a 100 meterslong roll. The extra amount of antisolvent was blown by second air knife equipped after the bath. The roll was annealed by passing through the hot air oven at $140^{\circ} \mathrm{C}$. A P3HT was dissolved in chlorobenzene/chloroform $(8: 2 \mathrm{by} \mathrm{v} / \mathrm{v})$ at a concentration of $55 \mathrm{mg} \mathrm{ml}^{-1}$, with Li-TFSI solution $\left(540 \mathrm{mg} \mathrm{ml}^{-1}\right.$ in acetonitrile) and TBP as dopants. P3HT was R2R gravure printed at a speed of $8 \mathrm{~m} \mathrm{~min}^{-1}$ and annealed at $80^{\circ} \mathrm{C}$ for $30 \mathrm{~s}$. The roll was cut into individual sheets and Au electrode was evaporated to complete the device structure.

Characterization. The top-view and cross-sectional image of perovskite films and solar cells were obtained by using field emission scanning electron microscope (SEM, Mira 3 LMU, Tescan) operated at $20 \mathrm{kV}$. Physical dimensions from the images were obtained by using ImageJ software (U.S. National Institutes of Health, https://imagej.nih.gov/ij/). X-ray diffraction spectra were obtained by using Rigaku smartlab X-ray diffractometer. The J-V curves and MPPT tracking curve were obtained by using a solar simulator (Newport, Oriel Class A, 91195A) with voltage sourcemeter (Keithley 2400) under $100 \mathrm{~mW} \mathrm{~cm}^{-2}$ illumination with standard AM1.5G condition. Light intensity was calibrated Si-reference cell certified by the NREL, USA. The measurement was performed under ambient atmosphere, scanned in range from -0.2 to $1.2 \mathrm{~V}$, with $10 \mathrm{~ms}$ of delay time. The samples were all masked with metal-mask having an active area of $0.096 \mathrm{~cm}^{2}$. The active area defined by metal mask was measured by using optical microscope. EQE was measured by using QUANTX-300 QE measurement system (Oriel Instruments) The Viscosity of solutions was measured by ARES-G2 Rheometer using $40 \mathrm{~mm}$ parallel plate geometry while retaining the temperature of solution at $25^{\circ} \mathrm{C}$. Fourier-transform Infrared (FT-IR) spectra was measured in ATR mode, by using compact FT-IR spectrometer ALPHA II (Bruker corporation). Time-resolved PL (TRPL) study was performed using an inverted-type scanning confocal microscope (MicroTime-200, Picoquant, Germany) with a $40 \times$ (air) objective. The lifetime measurements were performed at the Korea Basic Science Institute (KBSI), Daegu Center, Korea. A single-mode pulsed diode laser $(470 \mathrm{~nm}$ with a pulse width of $\sim 30 \mathrm{ps}$ ) was used as an excitation source. A dichroic mirror (490 DCXR, AHF), a $75 \mu \mathrm{m}$ pinhole, and a single-photon avalanche diode (PDM series, MPD) were used to collect emission from the samples. Time-correlated single-photon counting technique was used to count emission photons. TRPL images consisted of $200 \times$ 200 pixels were recorded using the time-tagged time-resolved data acquisition method.

Reporting summary. Further information on research design is available in the Nature Research Reporting Summary linked to this article.

\section{Data availability}

The data that support the findings of this study are available from the corresponding author upon reasonable request.

Received: 20 May 2020; Accepted: 16 September 2020; Published online: 13 October 2020

\section{References}

1. Stranks, S. D. et al. Electron-hole diffusion lengths exceeding 1 micrometer in an organometal trihalide perovskite absorber. Science 342, 341-344 (2013).
2. Stoumpos, C. C., Malliakas, C. D. \& Kanatzidis, M. G. Semiconducting tin and lead iodide perovskites with organic cations: phase transitions, high mobilities, and near-infrared photoluminescent properties. Inorg. Chem. 52, 9019-9038 (2013).

3. Lee, M. M., Teuscher, J., Miyasaka, T., Murakami, T. N. \& Snaith, H. J. Efficient hybrid solar cells based on meso-superstructured organometal halide perovskites. Science 338, 643-647 (2012).

4. Burschka, J. et al. Sequential deposition as a route to high-performance perovskite-sensitized solar cells. Nature 499, 316-319 (2013).

5. Jeon, N. J. et al. Solvent engineering for high-performance inorganic-organic hybrid perovskite solar cells. Nat. Mater. 13, 897-903 (2014).

6. Yang, W. S. et al. High-performance photovoltaic perovskite layers fabricated through intramolecular exchange. Science 348, 1234-1237 (2015).

7. Jung, E. H. et al. Efficient, stable and scalable perovskite solar cells using poly (3-hexylthiophene). Nature 567, 511-515 (2019).

8. Song, Z. et al. A technoeconomic analysis of perovskite solar module manufacturing with low-cost materials and techniques. Energy Environ. Sci. 10, 1297-1305 (2017).

9. Li, Z. et al. Scalable fabrication of perovskite solar cells. Nat. Rev. Mater. 3, 18017 (2018).

10. Chang, N. L. et al. Manufacturing cost and market potential analysis of demonstrated roll-to-roll perovskite photovoltaic cell processes. Sol. Energy Mater. Sol. Cells 174, 314-324 (2018).

11. Heo, Y.-J. et al. Printing-friendly sequential deposition via intra-additive approach for roll-to-roll process of perovskite solar cells. Nano Energy 41, 443-451 (2017).

12. Hwang, K. et al. Toward large scale roll-to-roll production of fully printed perovskite solar cells. Adv. Mater. 27, 1241-1247 (2015).

13. Dou, B. et al. Roll-to-roll printing of perovskite solar cells. ACS Energy Lett. 3, 2558-2565 (2018).

14. Galagan, Y. et al. Roll-to-roll slot die coated perovskite for efficient flexible solar cells. Adv. Energy Mater. 8, 1801935 (2018).

15. Kim, Y. Y. et al. Gravure-printed flexible perovskite solar cells: toward roll-toroll manufacturing. Adv. Sci. 6, 1802094 (2019).

16. Kim, J.-E. et al. Humidity-tolerant roll-to-roll fabrication of perovskite solar cells via polymer-additive-assisted hot slot die deposition. Adv. Funct. Mater. 29, 1809194 (2019).

17. Krebs, F. C., Tromholt, T. \& Jorgensen, M. Upscaling of polymer solar cell fabrication using full roll-to-roll processing. Nanoscale 2, 873-886 (2010).

18. Apilo, P. et al. Roll-to-roll gravure printing of organic photovoltaic modulesinsulation of processing defects by an interfacial layer. Prog. Photovolt. 23, 918-928 (2015).

19. Vilkman, M. et al. Gravure-printed $\mathrm{ZnO}$ in fully roll-to-roll printed inverted organic solar cells: optimization of adhesion and performance. Energy Technol. 3, 407-413 (2015).

20. Zheng, J. et al. Spin-coating free fabrication for highly efficient perovskite solar cells. Sol. Energy Mater. Sol. Cells 168, 165-171 (2017).

21. Li, X. et al. A vacuum flash-assisted solution process for high-efficiency largearea perovskite solar cells. Science 353, 58-62 (2016).

22. Kim, M. K. et al. Effects of temperature and coating speed on the morphology of solution-sheared halide perovskite thin-films. J. Mater. Chem. A 6, 24911-24919 (2018).

23. $\mathrm{Wu}, \mathrm{W}$. Q. et al. Bilateral alkylamine for suppressing charge recombination and improving stability in blade-coated perovskite solar cells. Sci. Adv. 5, eaav8925 (2019)

24. Sanchez, S., Hua, X., Phung, N., Steiner, U. \& Abate, A. Flash infrared annealing for antisolvent-free highly efficient perovskite solar cells. $A d v$. Energy Mater. 8, 1702915 (2018).

25. Zhou, Y. et al. Manipulating crystallization of organolead mixed-halide thin films in antisolvent baths for wide-bandgap perovskite solar cells. ACS Appl. Mater. Interfaces 8, 2232-2237 (2016)

26. Zhou, Y. et al. Room-temperature crystallization of hybrid-perovskite thin films via solvent-solvent extraction for high-performance solar cells. J. Mater Chem. A 3, 8178-8184 (2015).

27. Zhang, M. et al. Green anti-solvent processed planar perovskite solar cells with efficiency beyond 19\%. Sol. RRL 2, 1700213 (2018).

28. Yavari, M. et al. Greener, nonhalogenated solvent systems for highly efficient perovskite solar cells. Adv. Energy Mater. 8, 1800177 (2018).

29. Zhao, P. et al. Antisolvent with an ultrawide processing window for the onestep fabrication of efficient and large-area perovskite solar cells. Adv. Mater. 30, 1802763 (2018)

30. Alfonsi, K. et al. Green chemistry tools to influence a medicinal chemistry and research chemistry based organisation. Green. Chem. 10, 31-36 (2008).

31. Prat, D., Hayler, J. \& Wells, A. A survey of solvent selection guides. Green. Chem. 16, 4546-4551 (2014).

32. Alder, C. M. et al. Updating and further expanding GSK's solvent sustainability guide. Green. Chem. 18, 3879-3890 (2016). 
33. Cerón-Carrasco, J. P. et al. Solvent polarity scales: determination of new ET (30) values for 84 organic solvents. J. Phys. Org. Chem. 27, 512-518 (2014).

34. Tian, S. et al. A facile green solvent engineering for up-scaling perovskite solar cell modules. Sol. Energy 183, 386-391 (2019).

35. Schneider, C. A., Rasband, W. S. \& Eliceiri, K. W. NIH Image to ImageJ: 25 years of image analysis. Nat. Methods 9, 671-675 (2012).

36. Yang, M. et al. Perovskite ink with wide processing window for scalable highefficiency solar cells. Nat. Energy 2, 17038 (2017).

37. Vak, D. et al. 3D printer based slot-die coater as a lab-to-fab translation tool for solution-processed solar cells. Adv. Energy Mater. 5, 1401539 (2015).

38. He, M. et al. Meniscus-assisted solution printing of large-grained perovskite films for high-efficiency solar cells. Nat. Commun. 8, 16045 (2017).

39. Jeong, D. N. et al. Perovskite cluster-containing solution for scalable d-bar coating toward high-throughput perovskite solar cells. ACS Energy Lett. 4, 1189-1195 (2019).

40. Dai, X. et al. Scalable fabrication of efficient perovskite solar modules on flexible glass substrates. Adv. Energy Mater. 10, 1903108 (2020).

41. Eggers, H. et al. Inkjet-printed micrometer-thick perovskite solar cells with large columnar grains. Adv. Energy Mater. 10, 1903184 (2020).

42. Rong, Y. et al. Synergy of ammonium chloride and moisture on perovskite crystallization for efficient printable mesoscopic solar cells. Nat. Commun. 8 , 14555 (2017)

43. Cao, B. et al. Flexible quintuple cation perovskite solar cells with high efficiency. J. Mater. Chem. A 7, 4960-4970 (2019).

44. Huang, $K$. et al. High-performance flexible perovskite solar cells via precise control of electron transport layer. Adv. Energy Mater. 9, 1901419 (2019)

45. Wang, C. et al. Water vapor treatment of low-temperature deposited $\mathrm{SnO}_{2}$ electron selective layers for efficient flexible perovskite solar cells. ACS Energy Lett. 2, 2118-2124 (2017).

46. Gong, C. et al. Flexible planar heterojunction perovskite solar cells fabricated via sequential roll-to-roll microgravure printing and slot-die coating deposition. Sol. RRL 4, 1900204 (2020).

47. Zuo, C., Vak, D., Angmo, D., Ding, L. \& Gao, M. One-step roll-to-roll air processed high efficiency perovskite solar cells. Nano Energy 46, 185-192 (2018).

\section{Acknowledgements}

This work was supported by a grant from the Korea Research Institute of Chemical Technology (KRICT), Republic of Korea (KK1963-803 as "GO! KRICT project"), the Korea Institute of Energy Technology Evaluation and Planning (KETEP) from the Ministry of Trade, Industry \& Energy (20183010014470) and the National Research Foundation of Korea (NRF) funded by the Ministry of Science, ICT \& Future Planning (MSIP) of Korea (NRF-2016M3A6A7945503). The authors appreciate Mr. Dong Seok Ham with the assistance of viscosity measurement.

\section{Author contributions}

Y.Y.K., T.-Y.Y., R.S., and J.S. conceived ideas and contributed to design of experiments. Y.Y.K. tested and conducted experiments on the effect of various antisolvents. R.S. and A.K. provide R2R facilities. R.S. conducted the lab-scale gravure printing of the layers. Y.Y.K. and T.-Y.Y. fabricated devices. Y.Y.K. conducted characterization of the printed films and resulting devices. Y.Y.K., T.-Y.Y., R.S., and K.H. contributed to the roll-to-roll processing. Y.Y.K. and J.S. wrote the manuscript. N.J.J. aided in interpreting of the result. All the authors were involved in the discussion for data analysis and commented on the manuscript.

\section{Competing interests}

The authors declare no competing interests.

\section{Additional information}

Supplementary information is available for this paper at https://doi.org/10.1038/s41467020-18940-5.

Correspondence and requests for materials should be addressed to J.S.

Peer review information Nature Communications thanks the anonymous reviewer(s) for their contribution to the peer review of this work.

Reprints and permission information is available at http://www.nature.com/reprints

Publisher's note Springer Nature remains neutral with regard to jurisdictional claims in published maps and institutional affiliations.

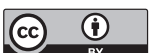

Open Access This article is licensed under a Creative Commons Attribution 4.0 International License, which permits use, sharing, adaptation, distribution and reproduction in any medium or format, as long as you give appropriate credit to the original author(s) and the source, provide a link to the Creative Commons license, and indicate if changes were made. The images or other third party material in this article are included in the article's Creative Commons license, unless indicated otherwise in a credit line to the material. If material is not included in the article's Creative Commons license and your intended use is not permitted by statutory regulation or exceeds the permitted use, you will need to obtain permission directly from the copyright holder. To view a copy of this license, visit http://creativecommons.org/ licenses/by/4.0/.

(C) The Author(s) 2020 